\title{
A Methodology for the Digitalization of the Residential Building Renovation Process through IDDS Ready Workflows ${ }^{\dagger}$
}

\author{
Alberto Armijo 1, Peru Elguezabal 1, Mohamed Elagiry ${ }^{2}$, Natalia Lasarte ${ }^{1}$ and Andrea Costa ${ }^{2, *}$ \\ 1 Tecnalia-Basque Research and Technology Alliance (BRTA), E-20009 Donostia-San Sebastián, Spain; \\ alberto.armijo@tecnalia.com (A.A.); peru.elguezabal@tecnalia.com (P.E.); natalia.lasarte@tecnalia.com (N.L.) \\ 2 R2M Solution, 27100 Pavia, Italy; mohamed.elagiry@r2msolution.com \\ * Correspondence: andre.costa@r2msolution.com \\ † Presented at the Sustainable Places 2020, Online, 28-30 October 2020; Available online: \\ https://www.sustainableplaces.eu/.
}

Published: 11 January 2021

\begin{abstract}
The European building industry is facing a strong increase of renovation processes, which are still non-cost-effective, involve unproperly coordinated stakeholders, are disturbing for the occupants, and imply important inefficiencies of the overall renovation process. In this context, digitalization and Building Information Modeling (BIM), as an enabler, is the key challenge that may drive the renovation interventions to ensure a successful process covering the whole value chain of actors to achieve its full potential. This research describes the OpenBIM methodology applied to transform the implicit knowledge from the stakeholders involved in a building renovation process into an IDDS digital process.
\end{abstract}

Keywords: BIM; OpenBIM; IDDS; retrofitting; digitalization

\section{Introduction}

This research deals with the systematization and digitalization of a building renovation process based on the elicitation of stakeholder's requirements and constraints carried out during the initial stages of EU funded H2020 BIM4REN project [1]. This identification involved the understanding of the connection among stakeholders, also between phases as well as the understanding of information exchanges, focusing on their needs to streamline the process and transform it into a leaner Integrated Design and Delivery Solutions (IDDS) approach. The methodology applied to transform the implicit knowledge from the stakeholders involved in a building renovation process and their current practices, which are not structured enough for automation, into a digital process is rooted on OpenBIM, with a focus on the exchange of information capabilities and the sharing of a single and updated source of information as a digital twin, allowing faster decision making to improve the design, building, and maintenance phases within the lifecycle of a building.

To illustrate the collaborative construction processes and information flows using natural language, the IDM (Information Delivery Manual) standard from OpenBIM was applied, complemented with the graphic language BPMN (Business Process Modelling Notation), which provides a standard representation to understand and represent the communication between participants and processes. Based on the description of the processes, the main objective is to define which user must provide and group together the required information and at which specific point in time. This information was formulated as Exchange Information Requirements (EIR) that focus on the high-level data to be exchanged during the process. 


\section{Renovation Activities. Current Use Cases, Barriers, and Requirements}

In order to capture the stakeholder's Use Cases, requirements, and constraints of the retrofitting sector and identify the opportunities of BIM implementation to overcome some of those barriers, a harmonized terminology in terms of BIM4Ren stakeholders and phases was defined for the specific case of the renovation process, based on standards used on new construction. To do so, first, bibliographic sources were consulted, and, in a second step, the terms were verified together with inquired stakeholders. The analysis was particularized to the barriers and requirements with the closest agents participating in the Pilots of BIM4Ren enabling them to tackle together the diagnosis from different perspectives.

\subsection{Current Barriers}

The assessment of barriers in renovation projects and activities as well as the potential to use BIM in that environment at the end of the overall process combining questionnaires, interviews, and workshops in [2], concluded that the main barriers of the digitalization raised specifically for the renovation process are not different to those identified for the new construction sector. The main concerns of the stakeholders in renovation projects as well as those in new construction are connected to time savings, cost savings, and collaboration process.

Nevertheless, beside those common barriers, the renovation has their specific hinders related to the data gathering of the building's characterization parameters and the reliability and management of this data representing the actual building, which is probably the main differentiation. Even if there is currently a set of promising technologies playing an important role for those data-gathering activities, there is still a big challenge to convert, manage, and interact with this information in formats compatible with collaborative processes. This is the key issue to solve in renovation and one of the main uncertainties among stakeholders interviewed, where the data accuracy represents one of the main concerns for architects and stakeholders intervening in the design phase.

\subsection{Current Requirents for Aplying BIM}

Although several drawbacks have been identified for the renovation process, it must be stated that not all of them may be solved using BIM. Thus, after this initial activity of identifying the main barriers, the BIM4Ren project focuses on the barriers that can be overcome by the BIM implementation. That allows defining the end user requirements in order to enable the use of BIM in renovation. The requirements are different depending on the stakeholder affected. The common key requirements derived from [2] are listed below:

- Integration of end user needs from the beginning and contrasted throughout the process, which need to be further on refined in a proposal for an IDDS-like process for renovation.

- Need of a digital platform to share information among stakeholders; alternatively, multiple platforms could be used if they are interoperable.

- Interlink of the phases to ensure an optimal continuum in the process and a correct usage of the different software tools.

- Common database of the existing building available for all stakeholders.

- Need of a standardized renovation process; in the BIM4Ren project, a generic process was proposed as a skeleton/template for other types of projects.

- Integration between cloud-sharing platforms and BIM information tools.

- Combined usage of new technology for data acquisition and easy conversion to format readable by design or assessment tools.

- For building owners and administration, specific requirements are brought up in order to boost the implementation of BIM. Some of these conditions are related to the integration of the BIM requirements into administrative processes, training, updating the public institution's hardware, etc. 


\section{BIM as an Opportunity}

\subsection{Technical and Organizational Interoperability}

Building Information Modelling (BIM) is considered a methodology and a process comprising the collaborative generation and evolution of digital representations of buildings and infrastructures as digital twins. These models provide the stakeholders involved in a building actuation with a trusted source of geometric and semantic information that can be extracted and exchanged to support decision making, such as better acoustic, energetic, or luminance simulations to improve the design, building and maintenance phases within the lifecycle of a building. BIM-based software is currently used in the architecture, engineering, and construction (AEC) industry as to plan, design, construct, and maintain diverse infrastructures, such as buildings, districts, bridges, roads, etc.

Several disciplines are involved in the construction and maintenance, including renovation, of a building. In most of the cases, those different actors will also be using different software applications, systems, and components. Since actors need to collaborate and work together, it would be desirable that those systems could function in sync and could exchange information under interoperability principles (i.e., how to connect systems and applications on a technical level). The exchange of information should also be achieved without special effort on the part of these actors. Interoperability is usually no issue when all actors use the same software. Thus, a software application that can cover all the domains and use cases would be required. There are several ways to solve the interoperability barriers, such as using open standards such as OpenBIM, which are fostered by neutral organizations for enabling and promoting information exchange. This is the most often used pattern leveraged in computing environments and in BIM methodology.

The AEC industry is characterized by its high volume of information processing and interaction between actors and software systems. Nowadays, more than ever with the proliferation of big data and $\mathrm{AI}$, information needs to be massively interpreted and exchanged by various actors. In recent years, the importance of interoperable software solutions continued to grow in AEC. Hence, interoperability has been often a major issue regarding barrier-free exchange of data and information. Thus, it is important to reduce the barriers that impede the flow of information by leveraging open standards.

In addition to technical interoperability problems, broadening the scope and definition of interoperability as well as the corresponding interoperability framework, BIM-oriented projects can also be more seamless in the flow of information. This means that interoperability covers other domains, in addition to technical, such as the organizational and procedural domains. For example, interoperability should also be achieved regarding business processes and how they hinder technical connections.

\subsection{OpenBIM}

The main organization promoting standardization in BIM is buildingSMART International (BSI) [3], which has numerous chapters by country or geographical area. Its main objective is to define, maintain, and promote open and neutral international standards, which can be grouped into categories, depending on their purpose.

- IDM (Information Delivery Manual) allows describing processes and information flows that occur between them using natural language. It is usually complemented with the graphic language BPMN (Business Process Modeling Notation) that provides a graphic notation to understand and represent the communication between participants and processes.

- The IFC (Industry Foundation Classes) is an object-oriented data model that allows the exchange of a BIM modeling without loss of data.

- BCF (BIM Collaboration Format) is a standard that is used to coordinate changes in the model throughout the project phase.

- The IFD (Information Framework for Dictionaries) is a mechanism to bring together different taxonomies and classification systems used in different countries. 
- The MVD (Model View Definition) is a subset of the IFC scheme being relevant for supporting a set of data exchange requirements. Thus, it enables translating processes into a formal specification on top of the IFC standard, which needs to be implemented by software interfaces in order to be able to fulfill the data exchange requirements stated by domain experts. Such an MVD is also used by BSI for software certification that helps select software packages.

\section{Methodology for Defining a Workflow}

In a first step of the methodology [4,5], the IDM OpenBIM standard was applied to root the digitalization of the building renovation process. In this regard, to streamline the digitalization of the renovation process, the Business Process Modeling Notation (BMPN2.0) has been leveraged for modeling the Use Cases. BPMN is meant to close the gap between business process design and process implementation; therefore, the general objective of BPMN is to support business process management by providing a standard notation that is easily understandable by the technical user, such as the technical developers, as well as by the business users, such as business analysts. This allowed the creation of IDDS diagrams that are easily readable by business analysts as they closely resemble a flowchart diagram. For the AEC industries to work seamlessly, it is advisable for all the participants of a project to precisely know when information must be communicated and what information needs to be communicated. In this regard, the IDM methodology aims to capture and specify processes and information flows during the life-cycle of a building (ISO 29481-1). The standard itself only describes the methodology on how to produce such a manual for the information exchange. Thus, based on the definition of the processes through BPMN2.0, the main objectives of the IDM are to define which user must provide and group together the required information and at which specific point in time, i.e., the required data formulated as Exchange Information Requirements (EIR) and listed in a tabular format.

After the application of the IDM standard, which is used to model the processes and high-level information exchange requirements, the Model View Definition (MVD) method is to be applied as a second step of the methodology. IDM does not offer low-level information or guidelines on the technology that should be used to exchange the information from the building models. Thus, such a guideline needs to be added separately to recommend the use of a certain subset of IFC. MVD is needed to satisfy one or many Exchange Requirements of the renovation process to foster software interoperability and enable the development of software tools and organizational mechanisms that create a seamless digital collaboration environment between the involved stakeholders in the renovation process.

\section{Definition of Digital Workflow for Renovation Activities}

To elaborate the BPMN workflows, several interviews were carried out with relevant stakeholders linked to the renovation processes, who were selected among the project pilots' participants, early adopters of the project, and other key agents, all of them belonging to the BIM4Ren extended community. The main goal of the interviews was to discover implicit knowledge from key actors having a relevant role in one or more renovation typologies. Each renovation work typology is considered as a Use Case (façade renovation, structural renovation, etc.). From the software engineering perspective, a Use Case is a list of actions that define the interactions between an actor and a system to achieve a goal or requirement. Table 1 shows a sample of a façade renovation Use Case that was identified from the consultations that were carried out. Each diagram was eventually mapped to a BPMN file. 
Table 1. Façade renovation Use Case identified during BIM4REN interviews.

\begin{tabular}{|c|c|c|}
\hline Workflow Perspective & Source & $\begin{array}{l}\text { Use Case } \\
\text { Type }\end{array}$ \\
\hline ID1. Main phases & BIM4REN own research & $\begin{array}{l}\text { General } \\
\text { diagram }\end{array}$ \\
\hline $\begin{array}{l}\text { ID2. Architect who developed the } \\
\text { Pilot }\end{array}$ & $\begin{array}{c}\text { Interview with the Architect of the pilot in } \\
\text { San Sebastian }\end{array}$ & $\begin{array}{l}\text { Specific } \\
\text { diagram }\end{array}$ \\
\hline $\begin{array}{l}\text { ID3. Private owner of a pilot's } \\
\text { dwelling }\end{array}$ & $\begin{array}{c}\text { Interview with the Owner of the pilot in } \\
\text { San Sebastian }\end{array}$ & $\begin{array}{l}\text { Spcific } \\
\text { diagram }\end{array}$ \\
\hline $\begin{array}{l}\text { ID4. Public owner who manages } \\
\text { social housing }\end{array}$ & Interview with an Early Adopter & $\begin{array}{l}\text { Specific } \\
\text { diagram }\end{array}$ \\
\hline
\end{tabular}

On the one hand, the first workflow called "ID1. Main phases" is a generic diagram that contains the lifecycle phases or tasks of a generic renovation process, as shown in Figure 1.

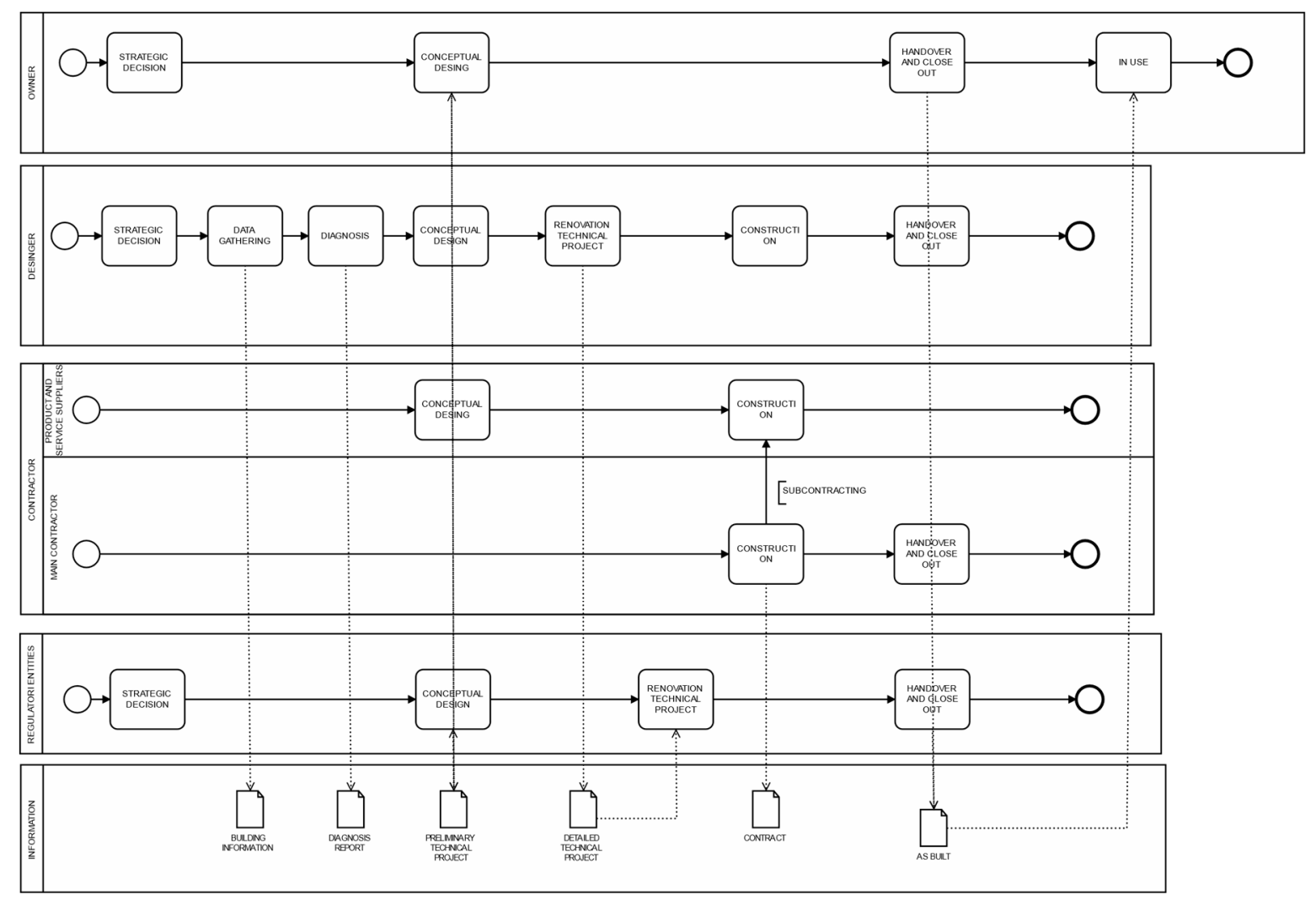

Figure 1. Generic Façade renovation BPMN (Business Process Modelling Notation) diagram (ID1).

On the other hand, the rest of specific BPMN workflows in Table 1 specify the tasks (subprocesses) involved in the lifecycle phases from the point of view of the stakeholders. For example, the BPMN diagram displayed in Figure 2 expands the generic diagram with the detailed tasks and Exchange Information Requirements (EIR) from the point of view of the architect in the façade renovation process in the BIM4Ren San Sebastian pilot (ID2). 


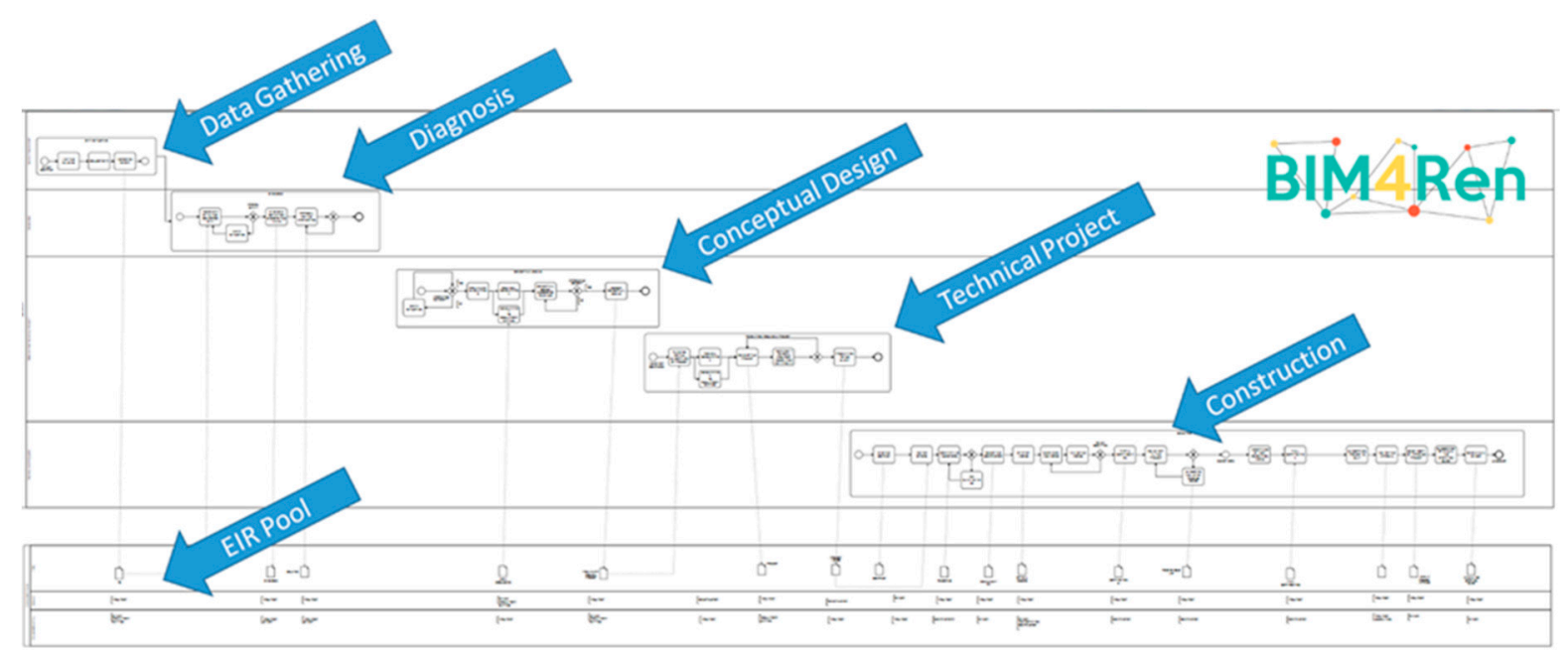

Figure 2. Generic façade renovation BPMN diagram (ID2).

The Exchange Information Requirements are collected for each Use Case in EIR tables containing the following basic information; Exchange name: Performed task and indicates the representation of the result (report, documentation, etc.); BPMN tasks involved: Tasks that are involved in the process of data exchange and assigned to the BPMN project phase; External Data (ED): Additional data delivered from external systems needed for the performance of the task; Sending Actor: Person who is responsible for the performance of the task and delivery of the information to the project partner; Receiving Actor(s): Person who receives the information and based on it performs the next project task; Possible Tools: Software that can be used in order to perform the task; Description Exchanged Data: Information that must be exchanged in order to perform the next task; Exchange Models: Type of models that must be exchanged in order to perform the next task, e.g., simulation graphs, reports, etc.; Data Exchange: File type/format that will be used in order to exchange the data between the actors and tools, e.g., gbXML, XLS, text/csv etc., IFC, PDF.

\section{Future Developments}

This research presents the activities carried during the digitalization of the building renovation process in the BIM4Ren project. It highlights the methodology applied to transform the implicit knowledge from the stakeholders involved in a renovation process and their current practices, which are currently not structured enough for automation, into a digital process. The outcomes of this research are the IDDS-BIM ready workflows that represent the renovation process and information requirements according to the sector segmentation, rooted on the analysis of stakeholders' requirements and needs. The IDDS-BIM based workflows were agreed by the French, Spanish, and Italian pilot partners and represent the current view of project partners.

The IDDS digital workflows designed in the research will support the definition of the system architecture and technical requirements by means of further applying the Model View Definition to describe the subset of the IFC schema that is needed to satisfy one or many Exchange Requirements of the AEC industry in the renovation process in particular. These IDDS-ready workflows, which will be revised and enhanced throughout the whole BIM4Ren project, will eventually incorporate the detailed EIR tables and associated Model View Definitions according to the approach described in this document and will enable an interoperable and efficient renovation process by means of bringing together the involved stakeholders and software tools.

Funding: This research was funded by Horizon 2020 Framework Programme (H2020-EU.2.1.5.2.), BIM4REN project, grant number 820773 .

Conflicts of Interest: The authors declare no conflict of interest. 


\section{References}

1. BIM Based Tools for Fast \& Efficient Renovation (BIM4Ren). Available online: https://bim4ren.eu/ (accessed on 23 October 2020).

2. Elagiry, M.; Marino, V.; Lasarte, N.; Elguezabal, P.; Messervey, T. BIM4Ren: Barriers to BIM Implementation in Renovation Processes in the Italian Market. Buildings 2019, 9, 200.

3. Building Smart International (BSI). Available online: https://www.buildingsmart.org/ (accessed on 23 October 2020).

4. Natalia Lasarte, Peru Elguezabal, BIM4REN, Building Information Modelling Based Tools \& Technologies for Fast and Efficient RENovation of Residential Buildings, D1.1-Stakeholders Requirements and Constraints; H2020 Project Report, Grant Agreement No. 820773. Public Deliverable, 4 June 2019.

5. Natalia Lasarte, Peru Elguezabal, BIM4REN, Building Information Modelling Based Tools \& Technologies for Fast and Efficient RENovation of Residential Buildings, D1.2-Digitalisation of the Building Renovation Process; H2020 Project Report, Grant Agreement No. 820773, Public Deliverable, 17 June 2019.

Publisher's Note: MDPI stays neutral with regard to jurisdictional claims in published maps and institutional affiliations.

(C) 2021 by the authors. Licensee MDPI, Basel, Switzerland. This article is an open access article distributed under the terms and conditions of the Creative Commons Attribution (CC BY) license (http://creativecommons.org/licenses/by/4.0/). 